\title{
The Relationship of Intact Parathyroid Hormone and Ionised Calcium in Secondary Hyperparathyroidism among Hemodialysis Patients
}

\author{
T Sudhakar ${ }^{1}$, Sabitha Kandi' ${ }^{2}$ B venugopal ${ }^{2}$, K. Bhagwan Reddy ${ }^{3}$, K. V. Ramana, ${ }^{4, *}$ \\ ${ }^{1}$ Department of Biochemistry, HOD lab services in-charge, Apollo Reach Hospital, Karimnagar, Andhra Pradesh, India \\ ${ }^{2}$ Department of Biochemistry, Chalmeda Anandrao Institute of Medical Sciences, Karimnagar, India \\ ${ }^{3}$ Department of Biochemistry, Prathima Institute of Medical Sciences, Karimnagar, India \\ ${ }^{4}$ Department of Microbiology, Prathima Institute of Medical Sciences, Karimnagar, India \\ *Corresponding author: ramana_20021@rediffmail.com
}

Received July 18, 2014; Revised July 30, 2014; Accepted August 15, 2014

\begin{abstract}
The parathyroid hormone (PTH) is a 115 amino acid precursor molecule; the intact PTH (iPTH) contains only 84 amino acids which is biologically active molecule. The PTH helps in regulation of serum calcium levels, either hyper or hypocalcaemia causes release of PTH. It regulates the serum calcium levels by increasing the flow of calcium from bone to extracellular fluid, by increasing the re-absorption of calcium from renal tubules and it also causes increased intestinal absorption of ionized calcium via Vitamin D. The iPTH is predominantly cleared in liver and kidney, the assay of iPTH is used for differently diagnosis of hypercalcaemia. The iPTH levels will be elevated if hypercalcaemia is due to exaggerated secretion of PTH otherwise it remains normal. Thus total calcium and ionized calcium levels will also be regulated by PTH. Secondary Hyper parathryoidism (SHPT) is a common complication of end stage renal disease (ESRD) in which there is hyperplasia of parathyroid gland. Thus, we conclude that there is an association of IPTH with ionized calcium in patients with SHPT and those undergoing hemodialysis. It is recommended that a by using a universal panel reference range in the assay of iPTH it is possible to minimize the complications in patients with chronic kidney disease.
\end{abstract}

Keywords: iPTH, ionized calcium, SHPT, hemodialysis, chronic kidney disease

Cite This Article: T Sudhakar, Sabitha Kandi, B venugopal, K. Bhagwan Reddy, and K. V. Ramana, "The Relationship of Intact Parathyroid Hormone and Ionised Calcium in Secondary Hyperparathyroidism among Hemodialysis Patients.” American Journal of Clinical Medicine Research, vol. 2, no. 4 (2014): 75-78. doi: 10.12691/ajcmr-2-4-3.

\section{Introduction}

Parathyroid hormone (PTH) is synthesized as a 115 amino acid precursor molecule prepro PTH. It is transferred to the cisternal space of the Endoplasmic Reticulum(ER), where 25 amino acid prepeptide is removed to yield pro PTH, it is then transported to Golgi apparatus, Pro PTH is acted on by enzyme to form mature PTH molecule. The mature PTH molecule contains 84 amino acids, the region of PTH from $1-34$ amino acids is biologically active [1]. PTH raises serum ionized calcium levels through direct action on bone and the kidneys. PTH causes demineralization of bone which in turn increases calcium flow from bone matrix to ECF and it causes enhanced re-absorption of calcium from renal tubules and increases excretion of phosphate from kidneys. Long term regulation of total body calcium by PTH is via Vitamin D, causes increased intestinal absorption of ionized calcium [2]. PTH undergoes proteolysis in liver and kidney, PTH is cleaved into three fragments, $\mathrm{N}$-terminal, C-terminal and middle fragments. N-terminal fragment disappears rapidly and is active whereas C-terminal fragment is cleaved by kidney has long half life [3]. The region of PTH from 1-84 amino acids is the intact PTH (iPTH), which is predominantly cleaved in liver and kidney. The assay of iPTH is used for the differential diagnosis of hypercalcaemia. If hypercalcaemia is due to the exaggerated secretion of PTH then the iPTH levels will be suppressed otherwise iPTH remains in normal range [4]. Secondary Hyperparathyroidism (SHPT) is a common complication of end - stage renal disease (ESRD). The decrease in functional renal mass results in hypocalcaemia, hyperphosphataemia and reduced calcitriol levels which stimulate the secretion of parathyroid hormone leading to the hyperplasia of the gland [5]. Ionized Calcium is normally better for accurately monitoring calcium status in renal diseases [6]. Ionized calcium is high in neonates at birth in blood then decreases by $10-20 \%$ after $1-3$ days, after a week ionized calcium concentration in the neonates stabilize at concentrations slightly higher than adults [7]. Ionized calcium represents physiologically active form of total calcium in the plasma [8]. Liver transplantation, citrated blood transfusions and neonatal hypocalcaemia are some examples of conditions where the measurement 
of ionized calcium is more preferred and meaningful than total calcium [9]. The advantages of measuring ionized calcium over total calcium are: [10]

a. There is no effect of venous occlusion or change of posture on the ionized calcium

b. More reliable indicator of calcium status of patients in certain clinical conditions

c. Physiologically active form of calcium(50\% of total calcium)

The measurement of ionized calcium was used to done by calculation method, but by the measurement of ionized calcium by ion-selective electrode (ISE) technology, the errors are less and this method gives accurate and precise values. The sample drawn for analysis of ionized calcium should be without anticoagulant, without airbubbles. The use of anticoagulants like heparin for measuring ionized calcium decreases the concentration of ionized calcium in the sample [11].

The present study aims to know the relationship of $\mathrm{iPTH}$ and Ionized calcium in secondary hyperparathyroidism of hemodialysis patients.

\section{Materials and Methods}

50 samples of hemodialysis patients with SHPT attending Nephrology OP in Apollo reach Hospital and 11 healthy control samples were also collected. The samples were estimated for iPTH, total calcium and ionized calcium.

\subsection{Blood Sample Collection}

The samples are collected in fasting conditions under aseptic environment. The samples are collected with the consent of the individuals. $5 \mathrm{ml}$ blood sample without any addition of anticoagulant is collected and allowed to clot, and then centrifuged at 3000rpm for 20 minutes. The serum obtained is used for the analysis.

\subsection{Exclusion Criteria}

- Hormonal Imbalance

- Diabetes mellitus
- Liver disease

- Vitamin D deficiency

\subsection{Inclusion Criteria:}

* Chronic Kidney Disease

Intact PTH assay Done by Chemiluminiscence method in Abbott hemiluminiscence Analyzer

Total calcium Done by O-Crespthalene Complexone method

Ionized Calcium Done by calculation ISE procedure

\section{Results}

The mean and SD values of patient group of iPTH are 321.8102 and 225.9290 and control group are 49.35 and 15.45 with $\mathrm{p}$ value 0.0001 extremely significant. The mean and SD values of ionized calcium are 3.8410 and 0.5255 and control group are 4.34 and 0.28 with p value 0.0001 extremely significant (Table1).

The mean difference between total calcium and iPTH are 314.1792 and $95 \%$ confidence interval of this difference is from the range of 377.5877 to 250.7707 . Similarly, the mean difference between ionized calcium and iPTH are 161.3970 with 95\% confidence interval of this difference ranging from 193.9148 to 128.8792 (Table1) (Figure 1).

Table 1. The statistical data of iPTH, Total calcium and ionized calcium

\begin{tabular}{|c|c|c|c|c|}
\hline Parameter & \multicolumn{2}{|c|}{ Mean +/- SD } & $\begin{array}{c}\text { 95\% confidence } \\
\text { interval }\end{array}$ & P value \\
\hline & Control & Patient & & \\
\hline Intact PTH & $\begin{array}{c}49.35+/- \\
15.45\end{array}$ & $\begin{array}{c}321.81+/- \\
225.9\end{array}$ & 126.82 & $0.001^{*}$ \\
\hline $\begin{array}{c}\text { Total } \\
\text { Calcium }\end{array}$ & $8.68+/-0.56$ & $\begin{array}{c}7.63+/- \\
1.24\end{array}$ & 65.04 & $0.001^{*}$ \\
\hline $\begin{array}{c}\text { Ionised } \\
\text { Calcium }\end{array}$ & $4.34+/-0.28$ & $\begin{array}{c}3.84+/- \\
0.52\end{array}$ & & $0.001^{*}$ \\
\hline
\end{tabular}

* Highly significant

The statistical analysis was done using Graph pad prism software

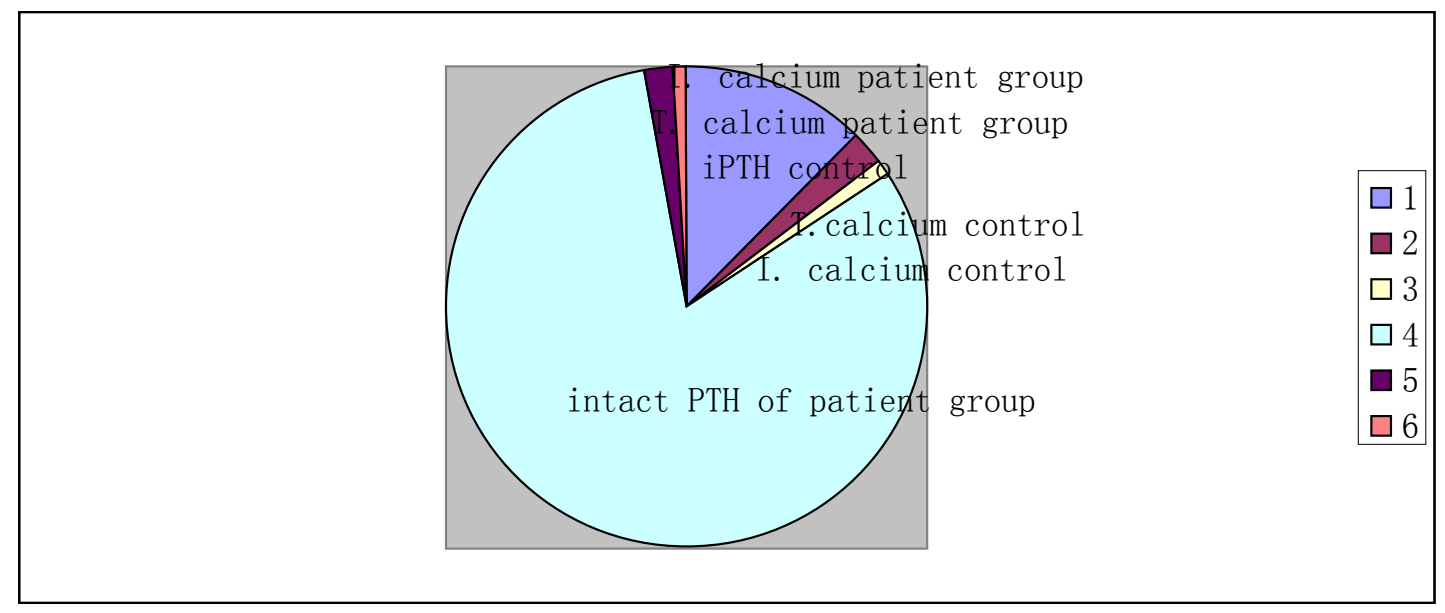

Figure 1. The pie diagram of intact PTH, Total Calcium and Ionized calcium of Patients and control group

The percent Recovery calculated for lower and higher normal levels of iPTH were $471.3 \%$ and $2233.8 \%$, total calcium are $93.3 \%$ \& $80.2 \%$ and Ionized calcium were $51.3 \%$ \& $92.8 \%$ (Table 2). 
Table 2. The Percent Recovery data of iPTH, Total calcium and ionized calcium

\begin{tabular}{|c|c|c|c|c|c|c|}
\hline & \multicolumn{2}{|c|}{ Intact PTH } & \multicolumn{2}{c|}{ Total calcium } & \multicolumn{2}{c|}{ Ionized calcium } \\
\hline & $\begin{array}{c}\text { Lower } \\
\text { Level }\end{array}$ & $\begin{array}{c}\text { Higher } \\
\text { Level }\end{array}$ & $\begin{array}{c}\text { Lower } \\
\text { Level }\end{array}$ & $\begin{array}{c}\text { Higher } \\
\text { Level }\end{array}$ & $\begin{array}{c}\text { Lower } \\
\text { Level }\end{array}$ & $\begin{array}{c}\text { Higher } \\
\text { Level }\end{array}$ \\
\hline $\begin{array}{c}\% \\
\text { Recovery }\end{array}$ & $471.3 \%$ & $2233.8 \%$ & $93.3 \%$ & $80.2 \%$ & $51.3 \%$ & $92.8 \%$ \\
\hline
\end{tabular}

The Percent recovery of iPTH, ionized calcium increased for higher normal range whereas the total calcium decreased for higher normal range.

The relationship between iPTH and total calcium is in sigmoid way similarly the curve obtained between the iPTH and ionized calcium is also a sigmoid curve (graph 1 and graph 2)

\section{PTH vs Ca++}

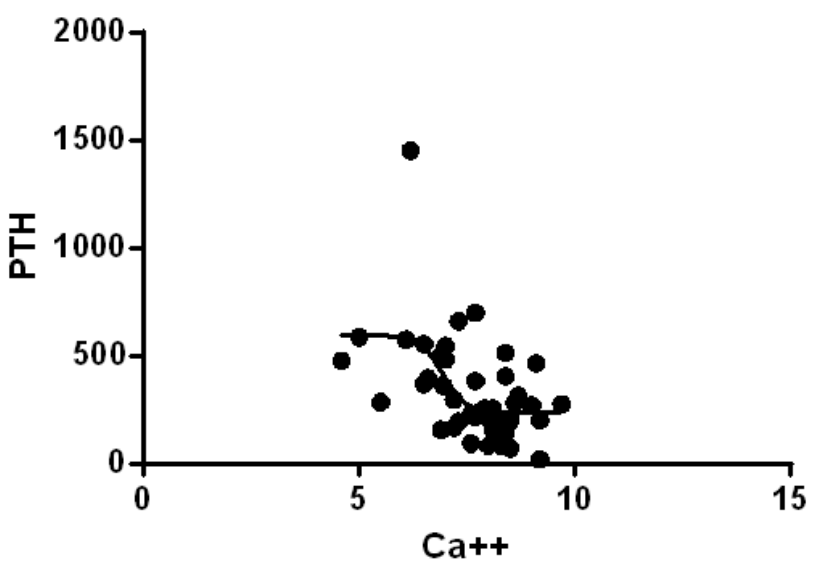

Graph 1. The sigmoid curve between iPTH and total calcium

\section{i PTH VS i ca+t}

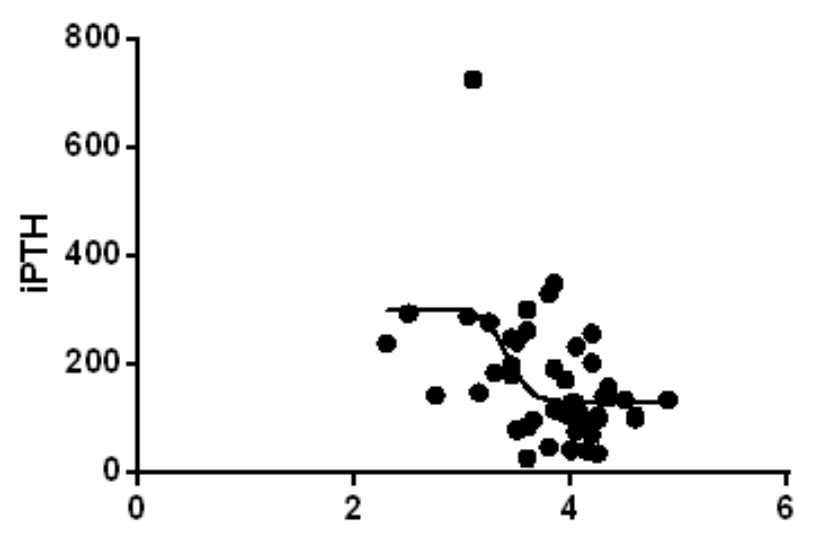

Ionised Calcium ( i ca++ ) (mg/dl)

Graph 2. The Sigmoid curve between iPTH and Ionized calcium (i ca ${ }^{2}$ )

\section{Discussion}

Nephrology guidelines recommend targets and treatment strategies to correct serum levels of phosphorus, calcium and parathyroid hormone because observational data suggest there is an association between these biomarkers and vascular disease which leads to death $[12,13]$. The burden of cardiovascular morbidity in individuals with chronic kidney disease necessitates the potential for serum levels of phosphorus, PTH and calcium to act as important modifiable risk factors [14]. Long term regulation of body total calcium by $\mathrm{PTH}$ is through vitamin D. There is a decreased expression of vitamin $\mathrm{D}$ receptor in both primary and secondary hyperparathyroidism which inhibit parathyroid gland proliferation [15,16]. Among ESRD beginning dialysis, initial PTH levels above 200pg/ml was associated with half the mortality of similar patients with PTH levels below $65 \mathrm{pg} / \mathrm{ml}$ controlling ionized calcium by monitoring its concentration can avoid problems from hypocalcaemia such as renal stones, other soft tissue calcification [17]. According to publications if iPTH value is less than $100 \mathrm{pg} / \mathrm{ml}$ there is $83 \%$ probability that the renal patient has adynamic low bone turnover disease [18]. In our study there are 8 cases with iPTH value less than $100 \mathrm{pg} / \mathrm{ml}$ thus, there is $83 \%$ probability of adynamic low bone turnover in these individuals. The PTH and serum calcium curves are sigmoid in primary and secondary hyperparathyroidism due to renal failure [19]. Similarly the intact PTH and ionized calcium curves are sigmoid [4]; PTH levels are elevated in SHPT usually associated with renal failure as a result of constant stimulation of parathyroid gland by low calcium levels. Hypocalcaemia accompanied by low PTH level seen in hypoparathyroidism either post surgical or idiopathic [20,21].

The relationship between iPTH and calcium levels or iPTH and ionized calcium can be expressed as sigmoid curve. The sigmoid curve obtained in the present study between iPTH and total calcium shows maximum calcium levels of $5 \mathrm{mg} / \mathrm{dl}$ corresponding to iPTH level of $600 \mathrm{pg} / \mathrm{ml}$ and minimum iPTH level of sigmoid curve is $200 \mathrm{pg} / \mathrm{ml}$ with total calcium levels of $9.5 \mathrm{mg} / \mathrm{dl}$. Similarly, the highest ionized calcium levels observed from sigmoid curve were $2.3 \mathrm{mg} / \mathrm{dl}$ with iPTH level

$480 \mathrm{pg} / \mathrm{ml}$ and lowest iPTH was 90pg/ml corresponding to ionized calcium of $4.8 \mathrm{mg} / \mathrm{dl}$. Thus, the iPTH level below $90 \mathrm{pg} / \mathrm{ml}$, total calcium below $5 \mathrm{mg} / \mathrm{dl}$, and ionized calcium below $2.3 \mathrm{mg} / \mathrm{dl}$ deteriorates the conditions associated with SHPT of chronic kidney disease. Thus, the parathyroid gland activity is mediated by a direct interaction of calcium ions with the calcium sensitive receptors [22]. There is a lack of comparability in the iPTH levels and it remained as a problem for the management of ESRD. The lack of comparability in iPTH levels is due to:

i. In ESRD patients due to decreased kidney function there is accumulation of large and small fragments of $\mathrm{PTH}$, which interfere with two antibodies that are intended to bind iPTH $(23,24,25)$.

ii. The standards or calibrators used to determine iPTH vary from company to company which would have potential to cause assay interference [26,27].

Thus, the iPTH levels can be used as a criterion in treating ESRD if there is a development of a universal reference panel to use in standardization of commercial iPTH assay [28]. Thus, by following universal reference panel determination of plasma intact PTH combined with plasma ionized calcium is a reliable means of studying the hyperparathyroidism associated with chronic renal disease [29].

\section{Conclusion}

The 95\% confidence interval mean difference between total calcium and iPTH is 314.792 and the $95 \%$ 
confidence interval mean difference between ionized calcium and iPTH is 161.3970 . If we follow a universal reference panel in standardization of iPTH assay then the iPTH value $<90 \mathrm{pg} . \mathrm{ml}$, ionized calcium $<2.3 \mathrm{mg} / \mathrm{dl}$, total calcium $<5 \mathrm{mg} / \mathrm{dl}$ can be used as cut off in determining the severity of SHPT in patients undergoing hemodialysis and is associated with chronic kidney disease. Evaluation of such parameters regularly may result in effective management of individuals with chronic kidney disease.

\section{References}

[1] Robert K. Murray, Daryl K. Granner, Peter A Mayes, Victor W. Rodwell. Harper's Biochemistry: Hormones that regulate calcium metabolism; chapter 47; 25 ${ }^{\text {th }}$ edition, Mc Graw Hill Publishers; 2000; 568-569.

[2] Armitage EK. Parathyrin (Parathyroid hormone): Metabolism and methods for assay. Clin Chem 1986; 32: 418-424.

[3] Blind E, Schmidt - Gayak H, Scharla S, Flentje D, Fischer S, Goehring $\mathrm{U}$ et al.,. Two -site Assay of intact parathyroid hormone in the investigation of primary hyperparathyroidism and other disorders of calcium metabolism compared with a mid region assay. J Clin Endocrinol Metab 1988; 67: 353-60

[4] Francis S. Greenspan, David G. Gardner. Basis and clinical Endocrinology: Mineral Metabolism and metabolic bone disease chapter 8; $6^{\text {th }}$ edition, Mc Graw Hill Publishers; 2000; 277-278.

[5] Silver J, Kilav R and Naveh-Many T. Mechanism of secondary hyperparathyroidism. American Journal of Physiology. 2002; 283 F367-376.

[6] Buritt MF, Picrides AM. Comparative studies of total and ionized calcium in serum in normal subjects and patients with renal disorders. Mayo Clin Prac 1980; 55: 606-13.

[7] Lenssar KMC, Vandenbergh. Ionised calcium plays a role in controlling BP during dialysis. Blood Purif 1989; 7: 233-239.

[8] Gidenne S, Vigezzi JF, Delacour H, Damiano J, Clerc Y. Direct determination or estimated value of plasma ionized calcium: indications and limits. Ann Biol Clin (Paris). 2003:61(4): 393 -9.

[9] Forman DT, Lorenzo L. Ionised calcium: its significance and clinical usefulness. Ann Clin Lab Sci. 1991:21(5): 297-304.

[10] Robertson WG. Measurement of ionized calcium in body fluids a review. Ann Clin Biochem. 1976; 13(6): 540-8.

[11] Soong WJ, Wang HZ, Hwang B. Heparinization of blood decreases ionized calcium concentration. Zhonghua Yi Xue Za Zhi(Taipei). 1991; 47(5): 331-5.

[12] National Kidney Foundation. K/DOQI clinical practice guidelines for bone metabolism and disease in chronic kidney disease. Am J Kidney Dis. 2003; 42(4): (suppl 3) S1- S201 (pub med).

[13] Kidney disease: Improving Global Outcomes (KDIGO) CKD MBD Work group. KDIGO clinical practice guidelines for the diagnosis evaluation, prevention, and treatment of chronic kidney disease - mineral \& bone disorder (CKD-MBD). Kidney Int. 2009; 76 (suppl 113) S1-S130.

[14] Suetonia C. Palmer, Andrew Hayen, Petra Macaskill, Fabio Pellegrini, Jonathan C. Crig, et al. Serum levels of Phosphorus, Parathyroid hormone, and calcium and risks of death and cardiovascular disease in individuals with chronic kidney disease. JAMA. 2011; 305(11): 1119-1127.
[15] Carling T, Rastad J, Szabo E, Westin G \& Akerstrom G. Reduced parathyroid vitamin $\mathrm{D}$ receptor messenger ribonucleic acid levels in primary and secondary hyperparathyroidism. Journal of Clinical Endocrinology and Metabolism. 2000; 85: 2000-2003.

[16] Lewin E, Garfia B, Recio FL, Rodriguez M \& Olgaard K. Persistent downregulation of calcium sensing receptor mRNA in rat parthyroids when severe secondary hyperparathyroidism is reversed by isogenic kidney transplantation. Journal of the American Society of Nephrology. 2002; 13: 2110-2116.

[17] Saha H, Harmoinen A, Pietila K, Morsky P, Pasternack A. Measurement of serum ionised Vs total levels of Magnesium and calcium in hemodialysis patients. Clin Nephrol 1996; 46(5): 32631.

[18] Monier-Faugere, Malluche et al. Improved assessment of bone turnover by the PTH(1-84)/ large C-PTH fragments ratio in ESRD patients. Kidney International. 2001; 60:1460-1468.

[19] Mizunashi K, Furukawa Y, Goto MM, Abe K. Sigmoidal curve shift in idiopathic hypoparatyroidism and pseudohypoparathyroidism. Am Soc Nephrology. 1998:62(4): 290-4.

[20] Christensen MS. Radio immuno assay of human parthyroid hormone Dan Med Bull 1979; 26: 157-73.

[21] Lepage R, Whittam S, Bertrand S, Bahsali G, D’Armour P. Superiority of dynamic over static reference intervals for intact, mid molecule and C-terminal parthyrin in evaluating calcemic disorders. Clin Chem. 1992; 38: 2129-35.

[22] C.E. Duran, Jose Vicente Torregrosa, Y. Almaden, H. Cacalejo, J. M. Campistol, M Rodriguez. Dynamics of calcium - regulated PTH secretion in secondary hyperparathyroidism; comparison between invivo Vs invitro responses. Nefrologia 2010; 30(1): 7377.

[23] Brossard, Cloutier M, Roy L, Lepage R, Gascon - Barre M, D'Amor P. Accumulation of a non (1-84) molecular form of parathyroid hormone $(\mathrm{PTH})$ detected b intact PTH assay in renal failure: importance in the interpretation of PTH values. J Clin Endocrino Metab 1996; 81: 3923-9.

[24] Brossard JH, lepage R, Cardinal H, Roy L, Dorais, et al., Influence of glomerular filtration rate on non (1-84) Parathyroid hormone (PTH) detected by intact PTH assays. Clin Cehm 2000; 46: 697-703.

[25] Lepage R, Roy L, Brossard JH, Rousseau L, Dorals C, Lazure C, et al.,. A non (1-84) circulating Parathyroid hormone (PTH) fragment interferes significantly with intact PTH commercial assay measurements in uremic samples. Clin Chem 1998; 44: 8059.

[26] Rej R, Drake P. The nature of calibrators in immunoassays: are they commutable with test samples? Must they be? Scand J Clin Lab Invest Suppl 1991; 205:47-54.

[27] Felder R, Holl RP, Martha J, Bauler G, Hellman P, Wills M, et al.,. Influence of matrix on concentrations of somatotropin measured in serum with commercial immunoradiometric assays. Clin Chem 1989; 35: 1423-6.

[28] Tom Cantor, Zan Yang, Nicolae Caraiani and Ekambaram Ilamathi. Lack of comparability of Intact Parathyroid hormone measurements among commercial assays for End Stage renal disease patients: Implication for treatment decisions. Clin Chem. 2006; 52: (9):1771-6.

[29] Pietila K, Morsky P, Pastemack A, Mustonen J, Koivula T. Intact $\mathrm{PTH}$, ionized calcium and calcium infusion test in the evaluation of hyperparathyroidism in chronic renal failure. Nephron 1987; 47(4): 284-9. 